\title{
A REVIEW OF THE TREATMENT OF CARDIOSPASM
}

\author{
BY \\ KINGSLEY LAWRANCE AND JOHN H. SHOESMITH \\ From the Department of Thoracic Surgery, The General Infirmary at Leeds
}

(RECEIVED FOR PUBLICATION MAY 11, 1959)

In 1948 Wooler reported the results of treatment in 47 patients with cardiospasm; he concluded that the treatment of choice was with the Negus hydrostatic dilator and, if this failed, Heller's operation. In 1950 Allison brought the total to 76 patients and recommended using the Negus dilator in all but three groups of patients, namely, (1) small children, (2) those not cured by the Negus dilator, and (3) those in whom the oesophagus had become so dilated and tortuous that the cardia could not be reached through the oesophagus. It is our intention to extend these reports and describe the results in 137 patients with cardiospasm who have been treated at Leeds.

Many different procedures have from time to time been advocated in the treatment of cardiospasm. Most of these were recently reviewed by Acheson and Hadley (1958), who found that the only procedures to have withstood the test of time were dilatation of the cardia through the oesophagoscope, usually with a Negus dilator, and cardiomyotomy, first described by Heller (1914). However, no definite conclusions appear to have been reached as to which of these two procedures is the more desirable, and, in fact, there has been a reluctance to use Heller's operation. Olsen, Harrington, Moersch, and Andersen (1951) reported 601 cases treated by the Negus dilator, but in 1958 Ellis, Olsen, Holman, and Code rather cautiously reported their results in 55 patients treated by Heller's operation; a similar cautious attitude can be detected in the report of 22 cases by Hawthorne and Nemir (1953) and that of Acheson and Hadley (1958) in 35 patients. By reviewing both the results of treatment and the trend of treatment in this series, it is intended to demonstrate a choice between the two procedures and dispel some of the doubts about Heller's operation.

MATERIAL.-One hundred and fifty-nine patients are listed in the records with a diagnosis of cardiospasm, and 22 of these were rejected because of doubt about the diagnosis or incomplete documentation, leaving a total of 137 .
These patients were seen between 1939 and August, $1956 ; 74$ were women and 63 were men. The age distribution (as recorded when the patient was first seen) is shown in Fig. 1. The high incidence in the fifth and sixth decades was noted by Allison and is an expression of the time that many patients are prepared to tolerate symptoms.

\section{Clinical Features and Diagnosis}

The patients' symptoms were grouped under six headings: (1) Dysphagia, (2) pain, (3) vomiting (regurgitation was included because many patients fail to distinguish between them), (4) loss of weight, (5) anorexia and indigestion, and (6) cough and sputum.

In 105 patients, dysphagia was the predominant symptom, but 32 in this series failed to mention it. Forty-one patients complained of pain, usually retrosternal. Sixty-six patients had vomiting and/or regurgitation. Only 45 patients noticed any loss of weight. Of the 10 patients who complained of anorexia and indigestion, none was shown to have a peptic ulcer and in fact there were only three patients in the series who had a peptic ulcer. Ten patients complained of a cough and sputum, of which five had physical signs. A further eight patients, although not complaining of respiratory symptoms, were found to have pneumonic complications.

Tolerance of symptoms, already mentioned, was marked in this series. Sixty-seven waited for more than five years before seeking treatment, 25 waited more than 20 years, and one for over 40 years (Table I).

Cardiospasm, it is often said, has a functional background, but although Allison stated that

TABLE I

DURATION OF SYMPTOMS BEFORE SEEKING RELIEF

\begin{tabular}{c|c|c|c|c|c}
\hline $\begin{array}{c}1 \\
\text { Year }\end{array}$ & $\begin{array}{c}1-2 \\
\text { Years }\end{array}$ & $\begin{array}{c}2-5 \\
\text { Years }\end{array}$ & $\begin{array}{c}5-10 \\
\text { Years }\end{array}$ & $\begin{array}{c}10-20 \\
\text { Years }\end{array}$ & $\begin{array}{c}20 \text { or }+ \\
\text { Years }\end{array}$ \\
\hline 16 & 17 & 37 & 23 & 19 & 25 \\
\hline
\end{tabular}




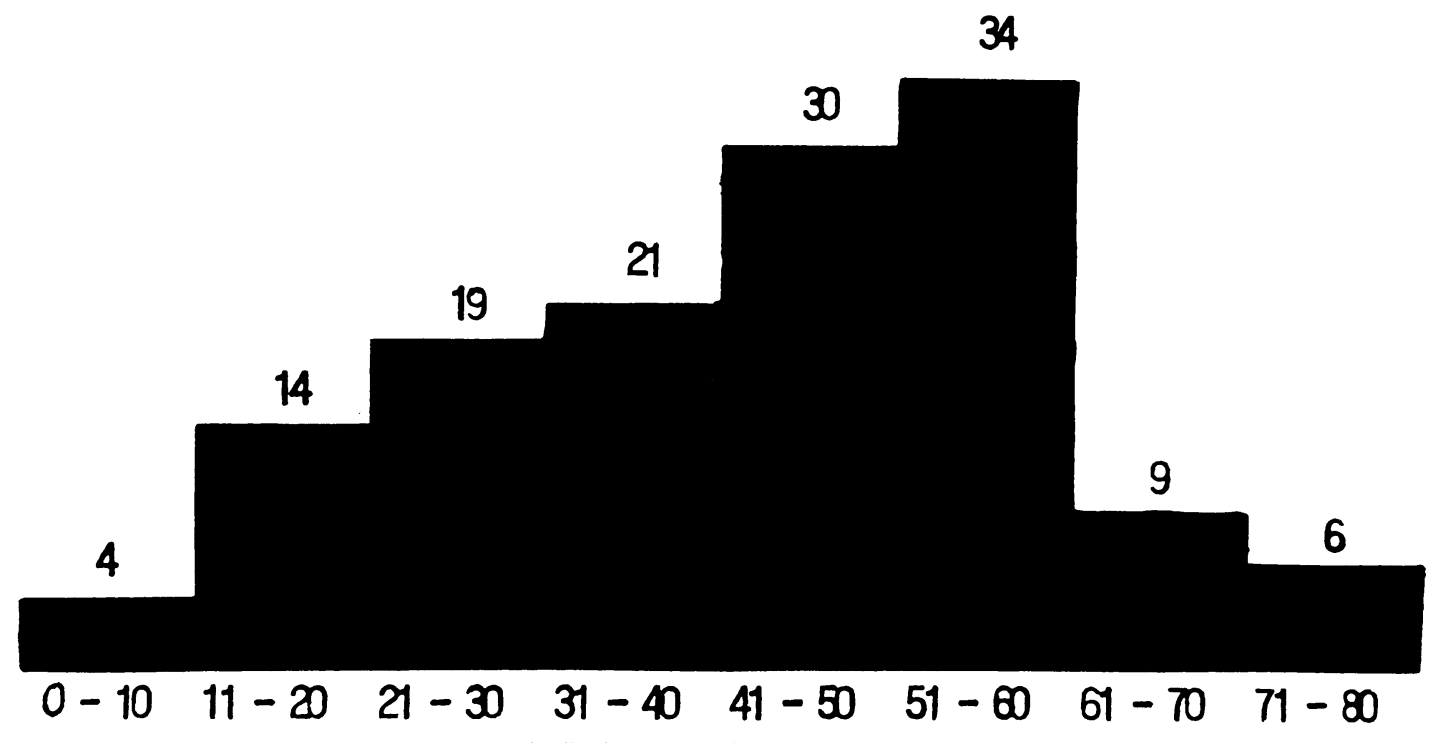

Fici. 1.-Age distribution (in decades) of patients with cardiospasm.

many patients were " odd." he did not describe a definite psychiatric condition. In this series. only 18 patients were described as being of a "worried" or "nervous" disposition and only two had seen a psychiatrist.

\section{DIAGNOSIS}

The diagnosis was made on clinical grounds. radiological appearances, and endoscopic findings. Most reliance was placed on the radiological features, the following criteria being necessary: Fluid barium was held up by spasm in the hiatal segment: the segment was smooth and had a beak-like appearance. but above this the oesophagus was dilated and secondary and tertiary contractions occurred.

Only eight patients of the series failed entirely to fulfil these criteria. In two cases the films and reports were not available: in one the radiological appearances were compatible with "very early cardiospasm": the diagnosis in two others was justified by the clinical findings, appearances at oesophagoscopy, and subsequent progress. One was described as "megaoesophagus " but in all other respects behaved as a case of cardiospasm. The remaining two were described as "unusual" and probably represent early cases of cardiospasm: the barium was held up at the lower end of the oesophagus and tertiary contractions were present. but the hold-up was temporary.

\section{ENDOSCOPIC FINDINGS}

All but seven paticnts were oesophagoscoped before treatment with fairly constant findings the oesophagus was dilated, the mucosa redun dant, and the cardia usually closed.

Twenty-six cases had evidence of oesophagitis in two of these the inflammatory changes had occurred after Negus bag dilatation and were the only two cases with oesophagitis following the use of the Negus bag in 102 patients. It was thought that the length of history or the age of the patients might be related to the incidence of oesophagitis, but this was not substantiated. There was a significant difference in the sex incidence: 18 of $\frac{\sigma}{3}$ the 24 patients were women, although in the whole series the sex distribution was approximately equal.

\section{TREATMENI}

The patients were grouped under the following headings according to the treatment received: $\bar{N}$ (1) No treatment. (2) miscellaneous, (3a) Negus $\sigma$ hydrostatic dilator. (3b) Negus hydrostatic dilator $N$ and Heller's operation, and (4) Heller's operation. స్ట

In the first group there were five patients : one refused treatment, two had had an operatione elsewhere, one was able to swallow if he took hot $\overline{\mathbb{D}}$ drinks, and one was apparently improved by $\stackrel{\mathscr{C}}{+}$ oesophagoscopy alone.

In the second group there were eight patients: $\frac{\vec{C}}{\bar{P}}$ three had had the von Mikulicz operation $\stackrel{P}{\square}$ (1904), one Hurst's bougies, and one required $\stackrel{\Phi}{\varrho}$ 
occasional bouginage. Two managed with octyl nitrite and one, who had surgery elsewhere, required resection of the lower oesophagus.

In Group 3a there were 59 patients and in Group $3 b 41$ patients, giving a total of 100 ; these two groups will be considered together. The only treatment found necessary in 59 patients was one, or occasionally two, dilatations with the Negus bag; 41 patients who had the same treatment were no better or only temporarily improved after two dilatations; all patients in this group subsequently had a Heller's operation, most of them within a year of the failed Negus dilatation. It is significant that many patients in the latter group obtained as good relief from the first dilatation as did the patients in Group 3a, but the improvement was short-lived. It follows that early relief from Negus bag dilatation is no indication of subsequent behaviour.

In the last group, there were 24 patients who had a Heller's operation as the primary procedure. Before 1951 only four patients had a Heller's operation as a primary procedure, and in two of these cases it was because a carcinoma was suspected. By 1952, 81 patients had been treated with the Negus dilator and 30 of these had later required a Heller's operation; this is a failure rate of $37.5 \%$, which approaches the failure rate of $41 \%$ for the whole series. It is not surprising to find that, after 1952, 20 patients had a primary Heller's operation; and also patients who did not respond to the Negus dilator never received more than two dilatations before a Heller's operation was performed, whereas before 1952 multiple dilatations were common.

Only two of the 24 patients in the last group required supplementary treatment; one had dysphagia in the early post-operative period and received a Negus dilatation with lasting relief. The other patient had had three unsuccessful operations before the Heller's operation and had dysphagia post-operatively. A dilatation was done with no improvement.

Heller's operation has been performed 65 times in this series.

\section{Follow-UP}

It was possib!e to follow up 118 of the 137 patients, and the follow-up period ranged from a minimum of two years to 16 years, with an average of 5.8 years.

Twelve of the 118 patients had died and the causes of death are shown in Table II; the cause of the "acute toxaemia" in Case 5 was unknown and the cause in Case 8 could not be determined
TABLE II

CAUSE OF DEATH IN 12 CASES

\begin{tabular}{|c|c|c|c|}
\hline $\begin{array}{l}\text { Case } \\
\text { No. }\end{array}$ & $\begin{array}{l}\text { Cause of } \\
\text { Death }\end{array}$ & $\begin{array}{l}\text { Treatment } \\
\text { for } \\
\text { Cardio- } \\
\text { spasm }\end{array}$ & $\begin{array}{c}\text { Interval } \\
\text { between } \\
\text { Treatment } \\
\text { and Death }\end{array}$ \\
\hline $\begin{array}{r}1 \\
2 \\
3 \\
4 \\
5 \\
6 \\
7 \\
8 \\
9 \\
10 \\
11 \\
12\end{array}$ & 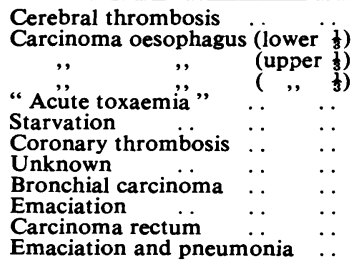 & $\begin{array}{l}\text { Negus } \\
\text {," } \\
\text { Hëler } \\
\text {," } \\
\text { Negus } \\
\text {,, } \\
\text {," } \\
\text {,, }\end{array}$ & $\begin{array}{l}5 \text { years } \\
11 \text { ", } \\
7 \\
6 \text { ", } \\
2 \text {," } \\
3 \text { months } \\
10 \text { years } \\
9 \text { ", } \\
9 \text { weeks } \\
3 \text { weeks } \\
3 \frac{1}{2} \text { years } \\
3 \text { weeks }\end{array}$ \\
\hline
\end{tabular}

but was not related to cardiospasm. Both Case 10 and Case 12 were in extremis when first seen.

The effect of treatment was assessed by having all patients answer the following questions :

(1) As a result of treatment, do you regard your swallowing as (a) normal, (b) improved, (c) unchanged, $(d)$ worse ?

(2) If the treatment only gave temporary improvement, (a) how long did it last? $(b)$ what has happened since?

(3) Have you found it necessary to have treatment at another hospital ?

(4) Are you taking a normal diet? If not, what diet are you having and why ?

From the answers obtained, the results of treatment in the various groups were as follows:

(1) No Treatment.-These patients remained unchanged apart from the two who had already had operations; these two regard their swallowing as improved and are able to eat a normal diet.

(2) Miscellaneous Treatment.-Two of the three patients who had a Mikulicz operation were followed up and both regard their swallowing as normal ; they also take a normal diet.

The patient who had occasional dilatations and the one who had had a resection both reported that they take a normal diet and that their swallowing is improved.

The patients taking octyl nitrite are both improved but cannot take meat. The last patient was not traced.

(3a) Negus Dilator.-Forty-nine of the 59 patients in this group were followed up. Twentyfour $(48.9 \%)$ of these regard their swallowing as normal and take a normal diet. Twenty-one $(42.8 \%)$ say their swallowing is improved, and 14 of these eat a normal diet. Four $(8.2 \%)$ say their swallowing is unchanged, though two can manage a normal diet. 
(3b) Failed Negus Dilator Followed By HelleR's Operation.-Thirty-six of the 41 patients in this group have been followed up. Nineteen $(52.8 \%)$ say their swallowing is normal and that they eat a normal diet.

Sixteen $(44.4 \%)$ have improved swallowing ; 12 take a normal diet and four a semi-solid diet. One was unchanged and died three months later from starvation.

(4) Heller's Operation Only.-Twenty-two of the 24 patients in this group have been followed up ; $12(54.5 \%)$ report their swallowing as normal and eat a normal diet. Ten $(45.4 \%)$ have found their swallowing improved and all except one take a normal diet.

In the whole series, Heller's operation was performed on 65 patients and 58 of these have been followed up. Thirty-one regard their swallowing as normal and eat a normal diet; 26 say their swallowing is improved, and 21 of them at a normal diet. Five, however, have to take a semi-solid diet and one a "plain" diet.

The results are summarized in Table III.

TABLE III

SUMMARY OF RESULTS OF TREATMENT IN PATIENTS FOLLOWED UP

\begin{tabular}{|c|c|c|c|c|}
\hline & \multirow{2}{*}{ Total } & \multicolumn{3}{|c|}{ Swallowing } \\
\hline & & Normal & Improved & Unchanged \\
\hline 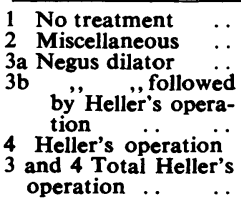 & $\begin{array}{r}5 \\
6 \\
49 \\
\\
\\
36 \\
22 \\
58\end{array}$ & $\begin{array}{l}\overline{2} \\
24(48.9 \%) \\
19(52.8 \%) \\
12(54.5 \%) \\
31(53.4 \%)\end{array}$ & $\begin{array}{l}2 \\
4 \\
21(42 \cdot 8 \%) \\
16(44 \cdot 4 \%) \\
10(45 \cdot 4 \%) \\
26(44 \cdot 8 \%)\end{array}$ & $\begin{array}{l}\frac{3}{4}(8 \cdot 2 \%) \\
1(2 \cdot 8 \%) \\
1(1 \cdot 7 \%)\end{array}$ \\
\hline
\end{tabular}

\section{Complications}

The patients who died and the complications resulting from the disease have been mentioned. There were few complications arising from treatment. Only two of the 102 patients treated with the Negus dilators developed oesophagitis. The pharynx was perforated by the instrument in one patient, but this was repaired and three months later a successful dilatation was performed.

No complications arose from the 65 Heller's operations performed through the left chest.

\section{Discussion}

It is difficult to assess the results of treatment of cardiospasm for several reasons. First, many patients with cardiospasm, although not suffering from a definite psychiatric illness, have been noted to be "odd" and this must affect their description of symptoms and results of treatment. Secondly, a high proportion of patients have had their trouble for so long that they may find it difficult to remember how they felt before the onset of their disease. Finally, there is no objective assessment which is entirely reliable.

It would be helpful if the changes in the radiological appearances could be used, but most writers confirm our findings that no relationship can be established between pre- and post-operative radiological and clinical changes.

Detailed evaluation of symptoms is unreliable because symptoms have different meanings to patients and observers, resulting in conflicting assessments (Acheson and Hadley, 1958). Ellis and others (1958) make use of weight changes in assessment and regard an increase as a favourable sign ; only $45(37.8 \%)$ of this series had lost any weight, so that comparison of weight before and after treatment is of limited value.

Patients with cardiospasm differ from normal people in two main respects; they nearly always have some difficulty in swallowing, and have to take care what they eat. If they are not on a "semi-solid" diet, they are careful to avoid meat and fish. Should treatment allow them to swallow in public without embarrassment, and to eat similar food to their fellow men, then such treatment can be regarded as successful.

The questions our patients were required to answer and the results obtained have been listed; questions 1 and 4 provide information of the type just mentioned, and if the patient was too optimistic about his treatment, it was felt that he would reveal this in answering questions 2 and 3 . Although this is not an ideal method of assessment, the difficulties have been stressed, and, in practice, the results obtained were consistent and there was little ambiguity.

In this series, the Negus dilator failed to give relief in $41 \%$ of cases; in the remainder it was regarded as satisfactory treatment. From the follow-up, however, although $48.9 \%$ regarded their swallowing as normal and $42.8 \%$ as improved, $8.2 \%$ were unchanged and so the actual failure rate of the Negus dilator is higher than $41 \%$. It can be said to offer an even chance of making the swallowing better or normal.

Heller's operation has no such initial failure rate, and the patient can be told that he will either find his swallowing normal or improved after operation. Nearly all the patients who had a Heller's operation after a Negus dilatation had failed were improved or normal; the results of 
a primary Heller's operation, however, appear to be slightly better.

All the patients in this series whose swallowing was normal after treatment were able to take a normal diet. If the swallowing had only been improved then some differences became apparent ; in Group 3a two-thirds could manage a normal diet ; in Group 3b three-quarters take a normal diet, and in Group 4 only one patient could not take a normal diet.

From these results, the Negus dilator emerges as an unreliable form of treatment for cardiospasm, offering at best an even chance of cure ; however, it can readily be used on out-patients, and if admission to hospital is difficult, one dilatation might cure the patient ; little would be lost if it failed. Very few complications arose from the use of the dilator, and none occurred after Heller's operation. In addition to being free from complication, we found that Heller's operation gave very good and consistent results, and it seems to be the treatment of choice for cardiospasm.

\section{SUMMARY}

One hundred and thirty-seven patients with cardiospasm were reviewed and 118 followed up. The difficulties inherent in evaluating the effect of treatment in this condition were noted and the method adopted for this series is described. The results indicated that Heller's operation is a safe and reliable treatment and should be the treatment of choice for cardiospasm.

\section{ADDENDUM}

In this series, only three cases had associated hiatus hernia and one case a "lax cardia." Since the period covered by this review, more attention has been paid to the state of the hiatus at operation, and the impression has been gained that the incidence of hernia or "lax cardia" is more common than appears from the cases reviewed. When a hernia or "lax cardia" is discovered in association with cardiospasm, it has been repaired by Allison's method (1951) after the cardiomyotomy.

The patients in this series were under the care of Professor P. R. Allison, Mr. G. H. Wooler, and Mr. J. A. Aylwin.

REFERENCES

Acheson, E. D., and Hadley, G. D. (1958). Brit. med. J., 1, 549. Allison, P. R. (1950). Proc, roy. Soc. Med., 43, 425. (1951). Surg. Gynec. Obstet., 92, 419.

Ellis, F. H., Jr., Olsen, A. M., Holman, C. B., and Code, C. F. (1958). J. Amer. med. Ass., 166, 29.

Hawthorne, H. R., and Nemir, P. (1953). Gastroenterology, 25, 349.

Heller, E. (1914). 'Mitt. Grenzgeb. Med. Chir., 27, 141.

Mikulicz, J von (1904). Disch med Wschr, 30,17.

Olsen, A. M., Harrington, S. W., Moersch, J. H., and Andersen, H. A. (1951). J. thorac. Surg., 22, 164 .

Wooler, G. H. (1948). Thorax, 3, 53 . 